\title{
FREQUENNCIA DE ANTICORPOS ANTI- Toxoplasma gondii EM PROPRIEDADES DE CRIAÇÃO DE CAPRINOS E OVINOS NO ESTADO DE PERNAMBUCO
}

\author{
Manoel de Souza Bispo ${ }^{1}$; Maria Aparecida da Gloria Faustino ${ }^{2}$; Leucio CÂMara Alves²; \\ Joaquín Hernán Patarroyo Salcedo ${ }^{3}$; Carlos Henrique de Souza ${ }^{4}$, Daliane Pontes de Sousa ${ }^{5}$, \\ MARILENE MARIA DE LimA ${ }^{6}$ \\ 1 Mestrando - PPGCV, Departamento de Medicina Veterinária,Universidade Federal Rural de Pernambuco - \\ manoelsb_2002@hotmail.com \\ 2 Prof. Adjunto - DMV - UFRPE \\ 3 Prof. Titular - DVT / UFV \\ 4 Mestrando - DVT UFV \\ 5 Graduação IC - CNPQ - UFRPE \\ 6 Doutoranda - PPGCV - UFRPE
}

RESUMO

Desenvolveu-se o presente estudo com o objetivo de averiguar a frequência de anticorpos contra $T$. gondii em propriedades de criação caprina e ovina de diferentes mesorregiões do Estado de Pernambuco. Foram coletadas amostras de sangue de 164 caprinos e 124 ovinos, as quais foram submetidas à técnica de Imunofluorescência
Indireta. Foram obtidas taxas de 47,6\% (78/164) e 48,4\% (60/124) de positividade para caprinos e ovinos, respectivamente. Diferenças significativas foram obtidas entre as taxas de infecção das diferentes mesorregiões tanto em caprinos como em ovinos.

PALAVRAS-CHAVE: caprino; imunofluorescência; ovino; Pernambuco; toxoplasmose.

ABSTRACT

\section{FREQUENCY OF THE ANTI- Toxoplasma Gondii ANTIBODY IN GOAT AND SHEEP FARMS IN THE STATE OF PERNAMBUCO - BRAZIL}

The present study was carried out in order to verify the presence of anti-Toxoplasma gondii antibodies in goat and sheep farms located in different mesoregions within the State of Pernambuco - Brazil. Blood samples were collected from 164 goats and 124 sheep and submitted to the indirect immunofluorescence technique. The results showed positive rates of $47.6 \%(78 / 164)$ and $48.4 \%$ (60/124) for goats and sheep, respectively. A significant difference of infection rates in the different regions was observed in both goats and sheep.

KEYWORDS: goat; immunofluorescence; Pernambuco; sheep; toxoplasmosis. 


\section{INTRODUÇÃO}

A caprino-ovinocultura é uma atividade de relevância no Nordeste brasileiro, principalmente nos estados da Bahia, Ceará, Piaú e Pernambuco, proporcionando uma fonte alternativa de proteína animal e contribuindo, significatiamente, na oferta de alimentos e peles de excelente qualidade (SOUZA, 1996). A produção e a produtividade desses animais ainda estão limitadas, devido a problemas sanitários, nutricionais e de manejo (VIEIRA et al., 1997). Grandes prejuízos à caprino-ovinocultura e, indiretamente, à saúde pública são causados por enfermidades infecciosas e parasitárias (PINHEIRO \& ALVES, 2003).

As desordens reprodutivas em caprinos e ovinos podem ser causadas por numerosos fatores (SMITH \& SHERMAN, 1994). Entre as causas de aborto nas referidas espécies são descritos desde o manejo inadequado das fêmeas até a ocorrência de doenças reprodutivas de origem infecciosa. Toxoplasma gondii é um dos agentes infecciosos envolvidos na etiologia de distúrbios reprodutivos em ovinos e caprinos.

Em caprinos, T. gondii tem sido responsável por infertilidade, podendo ocasionar abortos (DUBEY et al., 1986; DUBEY \& BEATTIE, 1988; DUBEY, 1990). SLOSÁRKOVÁ et al. (1999), em investigações realizadas na República Tcheca, em dois rebanhos importados da Dinamarca, revelaram um alto índice de abortos, nascimento de crias fracas e alta prevalência de anticorpos contra $T$. gondii em rebanho caprino Angorá, observando um excessivo aumento na prevalência de animais positivos pelo teste de fixação de complemento, indo de $9,4 \% \mathrm{em}$ 1994 , para $60,5 \%$ em 1996 , acompanhado por desordens reprodutivas.

Inquéritos sorológicos têm demonstrado a presença da infecção em rebanhos caprinos de diferentes estados do Brasil (SILVA et al., 2003). MAINARDI et al. (2003), pesquisando a soroprevalência de T. gondii em rebanhos caprinos no estado de São Paulo, encontraram positividade para o parasita em todas as sete regiões pesquisadas.

Nos rebanhos ovinos em todo o mundo têm-se encontrado altas taxas de prevalência de $T$. gondii, sendo a ingestão de alimentos contaminados com oocistos a mais importante fonte de infecção para essa espécie (SILVA et al., 2003). Estudo conduzido por SAWADOGO et al. (2005), na região de Marrakech, no Marrocos, confirma que os ovinos da região são portadores de cistos de $T$. gondii com uma taxa de $27,6 \%$.

Dados de WILLIAMS et al. (2005) revelaram que altos níveis de transmissão congênita pelo $T$. gondii foram mantidos durante todo o período de um estudo em ovinos, com $47-48 \%$ das gestações afetadas. As taxas de transmissão em gestações mal sucedidas (um ou mais cordeiros abortados, natimortos e mortos logo após o nascimento) foram consistentemente altas, com uma média de $91 \%$ de cordeiros infectados.

Além dos aspectos relacionados à sanidade animal, deve-se levar em consideração o aspecto zoonótico da toxoplasmose. A infecção pelo protozoário T. gondii é muito comum em humanos (DUBEY \& BEATTIE, 1988; REMINGTON et al., 1995), sendo difundida em todas as partes do mundo. Em inquérito epidemiológico conduzido em Belo Horizonte - MG, CHIARI et al. (1987) demonstraram haver uma correlação estatística significativa entre sorologia para $T$. gondii em humanos e a ingestão de leite de cabras. Segundo FIGUEIREDO et al. (2001), caprinos infectados representam importante fonte de infecção para humanos devido à ingestão de carne de animais infectados.

Diante do exposto, desenvolveu-se este trabalho com o objetivo de averiguar a frequência de anticorpos contra $T$. gondii em caprinos e ovinos no estado de Pernambuco.

\section{MATERIAL E MÉTODOS}

Foram selecionadas propriedades de criação caprina e ovina de diferentes mesorregiões do estado de Pernambuco, utilizando-se amostragem de conveniência (REIS, 2003), totalizando 18 propriedades (Tabela 1). Pelo mesmo critério de amostragem, foram selecionados animais de ambos os sexos, raças e idades variadas, sendo 164 caprinos e 124 ovinos. As coletas se deram no período de um ano, iniciadas em maio de 2004 e finalizadas em maio de 2005. 
Tabela 1 - Número de propriedades utilizadas conforme a mesorregião do estado de Pernambuco e a espécie explorada

\begin{tabular}{lccccc}
\hline & \multicolumn{3}{c}{ Tipo de criação } \\
\cline { 2 - 6 } \multicolumn{1}{c}{ Mesorregião } & Ovinos & Caprinos & Ovinos e caprinos & Total \\
\cline { 2 - 6 } & $\mathrm{n}$ & $\mathrm{n}$ & 2 & $\mathrm{n}$ & $\%$ \\
\cline { 2 - 6 } Região Metropolitana do Recife & 5 & 5 & 0 & 12 & 66,7 \\
Zona da Mata Norte & 1 & 1 & 0 & 2 & 11,1 \\
Agreste Central & 0 & 1 & 0 & 1 & 5,6 \\
Agreste Setentrional & 1 & 0 & 1 & 2 & 5,6 \\
Sertão Central & 0 & 1 & 3 & 18 & 11,1 \\
\hline Total & 7 & 8 & 100 \\
\hline
\end{tabular}

O estado de Pernambuco está localizado na região Nordeste, dividido por regiões que apresentam clima e precipitação pluviométrica distintas. $\mathrm{O}$ rebanho caprino e ovino em Pernambuco apresenta efetivo de 1.638 .514 e 1.487228 , respectivamente (IBGE 2009) e, embora encontrado em todas as regiões do estado, o maior efetivo está localizado nas regiões do Sertão Central e Sertão do São Francisco, no interior do estado, predominando clima seco (Semi-Árido), em que as precipitações pluviométricas são menores, quando comparados com os encontrados na região Metroplolitana e Zona da Mata.

Amostras sanguíneas foram coletadas por punção da veia jugular, após anti-sepsia com álcool iodado, utilizando-se agulhas hipodérmicas 30x10mm e seringas descartáveis de $10 \mathrm{~mL}$, e transferidas para tubos de ensaio, sem anticoagulante, devidamente esterilizados e identificados. Os tubos foram mantidos em recipiente adequado, à temperatura ambiente, para transporte até o Laboratório de Doenças Parasitárias dos Animais Domésticos Área de Medicina Veterinária Preventiva - Departamento de Medicina Veterinária - UFRPE, onde se procedeu a centrifugação a $156,8 \mathrm{~g}$ durante 5 minutos. O soro obtido foi acondicionado em recipientes com capacidade para $2 \mathrm{~mL}$, identificados e armazenados em freezer a $-20^{\circ} \mathrm{C}$ para posterior utilização no teste sorológico.

O teste sorológico foi conduzido no Laboratório de Biologia e Controle de Hematozoários e Vetores (LBCHV) - Instituto de Biotecnologia Aplicada à Agropecuária - Universidade Federal de Viçosa (BIOAGRO-UFV), empregando-se a técnica de Imunofluorescência Indireta (IFI), segundo CAMARGO (1974). Os soros foram diluídos para pesquisa de anticorpos da classe IgG, usando-se o fator de diluição quatro a partir de 1:16 até 1:256 em PBS
$\mathrm{pH} 7,2$, utilizando-se conjugado IgG de coelho antiovelha marcado com fluoresceína (FITC).

Após previa diluição em PBS pH 7,2, os soros caprinos e ovinos foram distribuídos nas lâminas sensibilizadas com taquizoítos de $T$. gondii cepa $\mathrm{RH}$ (cedidas pelo Laboratório de Toxoplasmose do Instituto de Ciências Biológicas da Universidade Federal de Minas Gerais), e mantidos em câmara úmida a $37^{\circ} \mathrm{C}$ por 40 minutos. Após serem retiradas da câmara, procedeu-se a lavagem das lâminas com PBS pH 7,2 por cinco minutos e com água destilada, pelo mesmo período de tempo; posteriormente, adicionou-se o conjugado anti-IgG de ovelha (BIOAGRO) marcado com isotiocianato de fluoresceína, que foi utilizado para as duas espécies. As lâminas foram mais uma vez mantidas em câmara úmida por 40 minutos a $37^{\circ} \mathrm{C}$, novamente lavadas com PBS pH 7,2 e com água destilada por cinco minutos, sendo então montadas em lâmina e lamínula, e examinadas em microscópio de fluorescência da marca Nikon Eclipse E600. Para controle positivo e negativo, foram utilizados soros conjugados anti-IgG de cão infectado e ovelha não infectada com $T$. gondii, respectivamente, previamente testados para essa finalidade. Os animais foram considerados sororreagentes a partir de títulos $\geq 1: 16$ (AMARAL et al., 1978; CHIARI et al., 1985; CHIARI et al., 1986).

Para a análise estatística foi utilizado o software SAS (Statistical Analysis System) na versão 8.0 para microcomputador, obtendo-se distribuições absolutas e percentuais dos dados, além do teste Qui-quadrado de Pearson e o teste Exato de Fisher quando as condições para utilização do teste Qui-quadrado não foram verificadas. Considerou-se o nível de significância de 5\% para a decisão dos testes estatísticos. 


\section{RESULTADOS E DISCUSSÃO}

Os dados relativos à infecção em caprinos à titulação de 1:16 encontram-se na Tabela 2, observando-se positividade de 47,6\% (78/164).

$\mathrm{O}$ resultado aqui obtido apresenta-se superior aos $30 \%$ de positividade encontrada por MACIEL (2005) em inquérito sorológico em caprinos criados nos municípios de Gravataí e Viamão, na grande Porto Alegre; aos 28,7\% registrados por FIGLIUOLO et al. (2004), que testaram 394 soros caprinos pertencentes a 19 propriedades no estado de São
Paulo; aos $14,47 \%$ verificados por MAINARDI et al. (2003) no inquérito sorológico realizado em 442 caprinos leiteiros pertencentes a sete municípios do estado de São Paulo; superior aos 19,5\% correspondentes a 34 animais positivos dentre os 137 caprinos testados em Uberlândia-MG por FIGUEIREDO et al. (2001), e à taxa de 8,0\% verificada por SILVA et al. (2002) em 100 amostras de soro caprino enviadas à Faculdade de Medicina Veterinária e Zootecnia, UNESP, em Botucatu, sendo todos os resultados citados encontrados por meio da IFI.

Tabela 2 - Frequência absoluta (n) e relativa (\%) de caprinos submetidos ao teste de Imunofluorescência Indireta para diagnóstico da infecção por T. gondii na titulação de 1/16 segundo a mesorregião

\begin{tabular}{|c|c|c|c|c|c|c|c|}
\hline \multirow{3}{*}{ Mesorregião } & \multicolumn{6}{|c|}{ Titulação de $1 / 16$} & \multirow{3}{*}{ Valor de p } \\
\hline & \multicolumn{2}{|c|}{ Positivo } & \multicolumn{2}{|c|}{ Negativo } & \multicolumn{2}{|c|}{ Total } & \\
\hline & $\mathrm{n}$ & $\%$ & $\mathrm{n}$ & $\%$ & $\mathrm{n}$ & $\%$ & \\
\hline Região Metropolitana do Recife & 57 & 68,7 & 26 & 31,3 & 83 & 100 & $\mathrm{p}^{(1)}=0,0001^{*}$ \\
\hline Zona da Mata Norte & 5 & 62,5 & 3 & 37,5 & 8 & 100 & \\
\hline Agreste Setentrional & 13 & 54,2 & 11 & 45,8 & 24 & 100 & \\
\hline Sertão Central & 3 & 6,1 & 46 & 93,9 & 49 & 100 & \\
\hline Total & 78 & 47,6 & 86 & 52,4 & 164 & 100 & \\
\hline
\end{tabular}

$(*)$ - Associação significativa ao nível de 5\%. (2) - Teste Exato de Fisher

Estudando cinco mesorregiões do Ceará em 2362 soros de caprinos de diferentes raças, sexo e idade, CAVALCANTE (2004) obteve positividade pela IFI de $31,3 \%$ à titulação de 1:16.

A positividade para $T$. gondii nos caprinos foi verificada em todas as propriedades. Esse achado assemelha-se à situação encontrada por FIGLIUOLO et al. (2004), que observaram a presença de pelo menos um caprino positivo para o $T$. gondii em todas as 19 propriedades analisadas no estado de São Paulo.

A taxa de positividade para o título de 1:64 foi de $36,0 \%$, com valores de $53,0 \%, 62,5 \%, 37,5 \%$ e 2,0\%, respectivamente, para a Região Metropolitana do Recife, Zona da Mata Norte, Agreste Setentrional e Sertão Central. Ao título de 1:256, obteve-se positividade de $26,8 \%$, as taxas encontradas para as respectivas mesorregiões foram de $37,4 \%, 37,5 \%$, $37,5 \%, 2,0 \%$.

Em todos os títulos analisados, observou-se associação estatisticamente significativa entre a frequência de infecção por $T$. gondii e a mesorregião a que pertenciam os animais (Tabela 2). A maior frequência obtida foi verificada na Região Metropolitana do Recife (RMR), no título de 1:16 (Tabela 2), com taxa de $68,7 \%$ (57/83), estatisticamente superior às obtidas nas demais mesorregiões, seguida da taxa de 62,5\% (5/8) obtida na Zona da Mata Norte no título de 1:16 (Tabela 2)

Dados previamente registrados da frequência de infecção por T. gondii em caprinos na Zona da Mata pernambucana demonstraram taxas inferiores, sendo $47,9 \%$ de positividade reportados por SILVA et al. (2003).

A taxa de $54,2 \%$ (Tabela 2) para caprinos localizados no Agreste, no presente estudo, apresentase próxima à registrada por SILVA et al. (2003) que indicaram taxa de 52,1\%.

Para a espécie ovina, foram encontrados $48,4 \%(60 / 124)$ de positividade ao título de 1:16 (Tabela 3), diferindo do resultado reportado por OGAWA et al. (2003), com $54,6 \%$ de soropositivos em títulos de anticorpos variando de 1:64 até 1:65536, empregando o mesmo teste sorológico, no município de Londrina - PR,

MASALA et al. (2003) obtiveram no período de 1999 a 2002 diferentes índices de positividade que variaram de 12,6\%, em 1999 a 44,5\%, em 2001, utilizando anticorpos específicos da classe IgG. SIL- 
VA et al. (2002) encontraram $23,0 \%$ de positividade à IFI com títulos variando de 1:16 a 1:256 para ovinos a partir de soros enviados a Faculdade de Medicina Veterinária e Zootecnia, UNESP, em Botucatu. No estado da Bahia, determinando a frequência de anticorpos contra $T$. gondii em ovinos, PITA GON-
DIN et al. (1999) obtiveram taxa de soropositividade de 7,27\% (12/165). LARSSON et al. (1980) avaliaram a frequência do Toxoplasma gondii em ovinos em diferentes regiões do Rio Grande do Sul, utilizando da reação de Sabin-Feldman, e encontraram percentual de $66,7 \%$ para título $\geq 1: 16$.

Tabela 3 - Frequência absoluta (n) e relativa (\%) de ovinos submetidos ao teste de Imunofluorescência Indireta para diagnóstico da infecção por $T$. gondii na titulação de $1 / 16$ segundo a mesorregião

\begin{tabular}{|c|c|c|c|c|c|c|c|}
\hline \multirow{3}{*}{ Mesorregião } & \multicolumn{6}{|c|}{ Titulação de $1 / 16$} & \multirow{3}{*}{ Valor de $\mathrm{p}$} \\
\hline & \multicolumn{2}{|c|}{ Positivo } & \multicolumn{2}{|c|}{ Negativo } & \multicolumn{2}{|c|}{ TOTAL } & \\
\hline & $\mathrm{n}$ & $\%$ & $\mathrm{n}$ & $\%$ & $\mathrm{~N}$ & $\%$ & \\
\hline Região Metropolitana do Recife & 39 & 51,3 & 37 & 48,7 & 76 & 100 & $\mathrm{p}(1)<0,0001^{*}$ \\
\hline Zona da Mata Norte & 11 & 55 & 9 & 45 & 20 & 100 & \\
\hline Agreste Setentrional & 10 & 100 & 0 & 0 & 10 & 100 & \\
\hline Sertão Central & 0 & 0 & 18 & 100 & 18 & 100 & \\
\hline Total & 60 & 48,4 & 64 & 51,6 & 124 & 100 & \\
\hline
\end{tabular}

$(*)$ - Associação significativa ao nível de 5\%. (1) - Teste Qui-quadrado de Pearson.

Levando em consideração as mesorregiões em relação aos ovinos, as maiores taxas de positividade ocorreram no Agreste Setentrional, apresentando $100,0 \%$ de positividade para os títulos 1:16 (Tabela 3) e $1: 64$, e $70,0 \%$ no título de $1: 256$, seguindo-se de $55,0 \%$ de positivos para os animais da Zona da Mata Norte ao título de 1:16, com diferenças estatisticamente significativas. Verificou-se também que as menores taxas de positividade foram provenientes da mesorregião do Sertão Central com $0 \%$ ao título de 1:16, 1:64 e 1:256. Tratando-se da mesorregião da Região Metropolitana do Recife, as taxa de positividade foram de $32,9 \%$, e $11,8 \%$ para os títulos 1:64 e 1:256, respectivamente, enquanto que a Zona da Mata Norte apresentou $40 \%$ de positividade tanto para o título de 1:64 quanto para $1: 256$.

Comparando-se o resultado em relação à mesorregião do Agreste para este experimento, o registro de SILVA et al. (2003), nesta espécie, apresenta taxa de positividade inferior $(32,4 \%)$.

KLUN et al. (2006), pesquisando rebanhos ovinos de três diferentes regiões da Sérvia, obtiveram taxas de $76,7 \%, 82,8 \%$ e $94,9 \%$, respectivamente, para rebanhos localizados nas regiões Centro-leste, Norte e Oeste.

Para ambas as espécies animais, as menores frequências foram verificadas no Sertão Central, com o máximo de $6,1 \%$ de positividade obtidos ao título de 1:16 para os caprinos, e sem verificação de positividade nos ovinos em nenhuma das titulações. O resultado apresentado em ambas as espécies para o Sertão Central pode estar relacionado às condições climáticas da região, considerando que o maior acumulado de chuvas no período de maio de 2004 a maio de 2005 ocorreu no mês de março de 2005, com $220,5 \mathrm{~mm}$ de chuvas, o que tornou o ambiente inapropriado para a manutenção dos oocistos no solo.

COSTA et al. (2001), trabalhando com soros de vacas, encontraram diferenças estatísticas para as frequências de infecção por $T$. gondii nos seis municípios estudados, atribuindo essas diferenças aos diversos ecossistemas das regiões.

As condições climáticas das diferentes mesorregiões do estado de Pernambuco divergem consideravelmente, sendo esse, possivelmente, o fator mais importante na diferença entre as taxas de infecção por T. gondii, principalmente em relação ao Sertão. No entanto, a RMR e a Zona da Mata do Estado apresentam as mesmas condições climatológicas, dessa forma, nesses resultados, pode-se levar em consideração as afirmações de SILVA et al. (2003), citando que na Zona da Mata de Pernambuco, a umidade elevada e o tipo de vegetação contribuem para a formação de um micro ambiente favorável à manutenção dos oocistos viáveis no solo por período prolongado. 


\section{CONCLUSÃO}

A infecção por Toxoplasma gondii está presente em caprinos e ovinos do estado de Pernambuco, estando a variação nas taxas de frequência associada às diferentes mesorregiões de criação.

\section{REFERÊNCIAS}

AMARAL, V. do; SANTOS, S. M.; REBOUÇAS, M. M. Sobre a prevalência de anticorpos anti-toxoplasma em soros de caprinos e ovinos procedentes, respectivamente, dos estados da Bahia e Rio Grande do Sul, Brasil. Biológico, São Paulo, n. 44, p. 331-340, 1978.

CAMARGO, M. E. Introdução às técnicas de imunofluorescência. Revista Brasileira de Patologia Clínica, São Paulo, v. 10, n. 1, p. 143-169, 1974.

CAVALCANTE, A. C. R. Epidemiologia e Caracterização do Toxoplasma gondii (Nicolle \& Manceaux, 1909) em Caprinos no Ceará. Tese (Doutorado em Ciências Área de Concentração em Protozoologia). Universidade Federal de Minas Gerais, Belo Horizonte. 2004. Disponível em: http://www.bdpa.cnptia.embrapa.br. Acesso em maio 2007

CHIARI, C. A.; LIMA, J. D.; ANTUNES, C. M. F. Reações de imunofluorescência indireta e de Sabin-Feldman na pesquisa de anticorpos anti-Toxoplasma gondii em soros de caprinos. Arquivo Brasileiro de Medicina Veterinária e Zootecnia, Belo Horizonte, v.37, n. 2, p.121-129, 1985.

CHIARI, C. A.; LIMA, J. D.; LIMA, W. S. Anticorpos circulantes em caprinos naturalmente infectados pelo Toxoplasma gondii. Arquivo Brasileiro de Medicina Veterinária e Zootecnia, Belo Horizonte, v. 38, n. 6 , p.889-898, 1986.

CHIARI, C.A.; LIMA, W.S.; ANTUNES, C.M.F.; LIMA, J.D. Soro-epidemiologia da toxoplasmose caprina em Minas Gerais, Brasil. Arquivo Brasileiro de Medicina Veterinária e Zootecnia, Belo Horizonte, v. 39, p. 587-609, 1987.

COSTA, G. H. N.; CABRAL, D. D.; VARANDAS, N. P.; SOBRAL, E. A.; BORGES, F. A.; CASTAGNOLLI, K. C. Freqüência de anticorpos anti-Neospora caninum e anti-Toxoplasma gondii em soros de bovinos pertencentes aos estados de São Paulo e de Minas Gerais. Ciências Agrárias, Teresina, v. 22, n. 1, p. 61-66, 2001.

DUBEY, J. P.; MILLER, S.; DESMONT, G.; THULLIEZ, P.; ANDERSON, WR. Toxoplasma gondii-induced abortion in dairy goats. Journal American Veterinary Medical Association, Schaumburg, n.188, p.159-162, 1986.

DUBEY, J. P. Status of toxoplasmosis in sheep and goats in the United States. Journal American Veterinary Me- dical Association, Schaumburg, n.196, p.259-262, 1990.

DUBEY, J. P.; BEATTIE, C. P. Toxoplasmosis of animals and man., Boca Raton: CRC Press, 1988. p. 220.

FIGLIUOLO, L. P. C.; KASAI, N.; RAGOZO, A. M. A.; DE PAULA, V. S. O.; DIAS, R. A.; SOUZA, S. L. P.; GENNARI, M. Prevalence of anti-Toxoplasma gondii and anti-Neospora caninum antibodies in goat from São Paulo State, Brazil. Small Ruminant Research, Amsterdam, v. 55, p. 29-32, 2004.

FIGUEIREDO, J. F.; SILVA, D. A. O.; CABRAL, D. D.; MINEO, J. R. Seroprevalence of Toxoplasma gondii infection in goats by the Indirect Haemagglutination, Immunofluorescence and Immunoenzymatic Tests in the region of Uberlândia, Brazil, Memórias do Instituto Oswaldo Cruz, Rio de Janeiro, v.96, n.5, p.687-692, 2001.

KLUN, I; DJURKOVIĆ-DJAKOVIĆ, O; KATIĆ-RADIVOJEVIĆ S.; NIKOLIĆ, A. Cross-sectional survey on Toxoplasma gondii infection in catlle, sheep and pigs in Serbia: Soroprevalence and risk factors. Veterinary Parasitology, Amsterdan, v. 135, p. 121- 131, 2006.

LARSSON, C. E.; JAMRA, L. M. F.; GUIMARÃES, E. C.; PATTOLI, D. B. G.; SILVA, H. L. L. Prevalência de toxoplasmose ovina determinada pela reação de SabinFeldman em animais de Uruguaiana, Revista Saúde Publica, São Paulo, n.14, p.582-588, 1980.

MACIEL, P. K. Inquérito sorológico para detecção de anticorpos de Toxoplasma gondii em caprinos (Capra hircus) criados nos municípios de Gravataí e Viamão, região da grande Porto Alegre, Rio Grande do Sul, Brasil. Acta Scientiae Veterinarie, Porto Alegre, v. 33 n. 2, p. 235236, 2005.

MAINARDI, R. S.; MODOLO, J. F.; STACHISSINI, A. V. M.; PADOVANI, C. R.; LANGONI, H. Soroprevalência de Toxoplasma gondii em rebanhos caprinos no estado de São Paulo. Revista da Sociedade Brasileira de Medicina Tropical, Rio de Janeiro v. 36, n. 6, p. 759-761, 2003.

MASALA, G.; PORCU, R.; MADAU, L.; TANDA, A.; IBBA, B. ; SATTA, G. ; TOLA, S. Survey of ovine and caprine toxoplasmosis by IFAT and PCR assays in Sardinia, Italy. Veterinary Parasitology, Amsterdan, v. 117, p. 15-21, 2003.

OGAWA, L.; NAVARRO, I. T.; FREIRE, R. L.; OLIVEIRA, R. C. O.; VIDOTTO, O. Ocorrência de anticorpos anti-Toxoplasma gondii em ovinos da região de Londrina no estado do Paraná. Ciências Agrárias, Teresina, n. 1, v. 24. p. 57-62, 2003.

PINHEIRO, R. R.; ALVES, F. S. F. Planejamento sanitário para pequenos ruminantes, 2003. Disponível em: $<$ www.nordesterural.com.br/dev/nordesterual $>$. Acesso em: junho 2006.

PITA GONDIM, L. F.; BARBOSAJR. H. V.; RIBEIRO 
FILHO, C. H. A.; SAEKI, H. Serological survey of antibodies to Toxoplasma gondii in goats, sheep. Cattle and water buffaloes in Bahia State, Brazil. Veterinary Parasitology, Amsterdam, n.82, p.273-276, 1999.

REIS, J. C. Estatística aplicada à pesquisa em Ciência Veterinária, 1 ed., 2003.p. 651.

REMINGTON, J. S.; MCTEOD R.; DESMONTS, G. Infectious diseases of the fetus and newborn infant, 4 th end. Philadelphia: Saunders, 1995. p. 140-267.

SAWADOGO, P.; HAFID, J.; BELLETE, B.; TRAN MANH SUNG, R.; CHAKDI, M.; FLORI, P.; RABERIN, H.; BENT HAMOUNI, I.; CHAIT, A.; DALAL, A. Soroprevalence of $T$. gondii in sheep from Marrakech, Morocco. Veterinary Parasitology, Amsterdan, v. 130, p. 89-92, 2005.

SILVA, A. V.; CUNHA, E. L. P.; MEIRELES, L. R.; GOTTSCHALK, S.; MOTA, R. A.; LANGONI, H. Toxoplasmose em ovinos e caprinos: estudo soro epidemiológico em duas regiões do Estado de Pernambuco, Brasil. Ciência Rural, Santa Maria, v. 33, n. 1, p. 115-119, 2003.

SILVA, A. V.; CUTOLO, A. A.; LANGONI, H. Comparação da reação de imunofluorescência indireta e do método de aglutinação direta na detecção de anticorpos anti-Toxoplasma em soros ovino, caprinos, caninos e felinos. Arquivos do Instituto Biológico, São Paulo, n. 1, v. 69. p. 7-11, 2002.
SILVA, N. R. S.; COSTA, A. J.; SOUZA, S. M. G. Prevalência de anticorpos anti-toxoplásmicos em ovinos determinada pela reação de imunofluorescência indireta (RIFI), no município de São Lourenço do Sul, R. S. Arquivo da Faculdade de Veterinária UFRGS, Porto Alegre, n. 8, p.89-92, 1980.

SLOSÁRKOVÁ, S.; SLOSÁRKOVÁ, S.; LITERÁK, I.; SKRIVÁNEK, M.; SVOBODOVÁ, V.; SUCHÝ, P.; HERZIG, I. et al. Toxoplasmosis and iodine deficiency in angora goats. Veterinary Parasitology, Amsterdan, n.81, p. $89-97,1999$.

SMITH, M. C.; SHERMAN, D. C. Goat Medicine, $1^{\mathrm{a}}$. Ed, Philadelphia, Lea \& Febiger, 1994, p. 620.

SOUZA, J. N. Demanda potencial de carne de caprinos e ovinos e perspectivas da oferta. In: EMBRAPA. Centro Nacional de Pesquisa de Caprinos. Relatório técnico do Centro de Pesquisa de Caprinos: 1987-1995. Sobral, 1996. p. 213-216. Disponível em: http://www.bdpa.cnptia.embrapa.br. Acesso em junho 2006.

WILLIAMS, R. H.; MORLEY, E. K.; HUGHES, J. M.; DUNCANSON, P.; TERRY, R. S.; SMITH, J. E.; HIDE, G. High levels of congenital transmission of Toxoplasma gondii in longitudinal and cross-sectional studies on sheep farms provides evidence of vertical transmission in ovine hosts. Parasitology, New York, v. 130, p. 301-307, 2005. 